\title{
Co morbidity as a risk factor for CABG patients of elderly and senile age
}

\section{Introduction}

Coronary artery bypass grafting $(\mathrm{CABG})$ is one of the most effective methods of myocardial revascularization and restoration of quality of life in patients with coronary heart disease (CHD). ${ }^{1}$ A characteristic feature of IHD is that it is observed with clinical manifestations mainly in patients over the age of 60 years. The increase in the multiplicity of diseases with age reflects, first of all, involutional processes (multimorbidity), and the deterministic possibility of their combination (comorbidity) remains a very complex problem..$^{2-4}$ In the presence of a plurality of diseases in one patient there is not just a summation of two or more changes in the body, but an extremely complex reaction, leading to significant changes in the clinical manifestations, course and outcomes of each of the associated diseases. ${ }^{5,6}$ Despite the fact that in leading clinics hospital mortality after CABG does not exceed $1-2 \%$, in the presence of multi - comorbidity the risk of complications and adverse outcomes becomes high. ${ }^{7,8}$ In modern cardioanesthesiology there are no generally accepted methods of risk assessment and preoperative preparation for coronary bypass surgery, depending on the presence of concomitant and/or associated pathology, taking into account age differences. ${ }^{9}$

\section{Objective}

To study the incidence of concomitant diseases of the circulatory, respiratory, digestive and genitourinary systems to improve the quality of prognosis of complications and adverse outcomes in coronary artery bypass grafting in patients with coronary artery disease, including elderly and senile patients.

\section{Materials and methods}

Materials and methods: 152 patients (men were 69.7\%, women$30.3 \%$ ) were observed who underwent planned surgery for coronary artery disease in the Altai regional clinical hospital. The mean age of patients at the time of surgery was $60.4 \pm 7.1$ years. The proportion of patients over 60 years of age amounted to $44.1 \%$ (67 patients). Coronary artery bypass grafting (CABG) was performed according to the indications in conditions of artificial circulation and cold cardioplegia. All patients underwent clinical and instrumental examination taking into account Recommendations for myocardial revascularization (2018). Patients who underwent repeated CABG, emergency $\mathrm{CABG}$, combined interventions on coronary arteries, myocardium and heart valves were excluded from the study. The index of comorbidity was assessed by Charlson ME et al. as modified by R. A. Deyo et al. The risk of operational lethality was assessed using European System for Cardiac Operative Risk Evaluation II (2011) (http://www.euroscore.org/).

\section{Results and discussion}

It should be noted that more than a half of the 46 women (61.0\%) admitted for surgical treatment were over 60 years. The average age of men was $58.5 \pm 5.9$, women- $63.8 \pm 6.4$ years $(\mathrm{p}<0.05)$. The analysis of clinical manifestations revealed age differences: for example, the II class by CCS, as well as a history of myocardial infarction (MI) were more often diagnosed in elderly patients, while in anamnesis of
Volume 4 Issue 3 - 2019

\author{
Klester EB,' Shoykhet Ya N,' Elykomov VA,' \\ Rudakova DM ${ }^{2}$ \\ 'Altai state medical University, Ministry of health of the Russian \\ Federation, Russia \\ ${ }^{2}$ Regional state budgetary institution of health care Altai regional \\ clinical hospital, Russia
}

Correspondence: Klester EB, Altai state medical University, Ministry of health of the Russian Federation, Barnaul, Russia, Email klester@bk.ru

Received: March 03, 2019 | Published: May 21, 2019

women were more often diagnosed with small focal MI (53.8\% vs. $22.1 \%$, $\mathrm{p}=0.04$ ), which is likely due to more frequent lesions of small branches of the coronary arteries. Elderly patients were characterized by a more pronounced angina clinic with a predominance of the III class by CCS and atypical manifestations such as vasospastic angina with a number of night attacks and a satisfactory condition during the day, as well as an increase in the frequency of painless myocardial ischemia diagnosed by Holter ECG monitoring and more severe manifestations of chronic heart failure.

In 152 patients, 432 diseases were detected, per patient an average of $3.2 \pm 0.9$ diseases, in addition to the main (IHD). The absence of co morbidities was registered only in $5.3 \%$ of patients. More than a third of patients $(59,38.8 \%)$ had more than 3 concomitant diseases. The most frequently were diagnosed with arterial hypertension $(84,2 \%$; $95 \%$ CI,75.2 per- 89,1$)$, encephalopathy $(77,6 \% ; 95 \%$ CI, 70.2 to $82,4)$, diseases of the digestive $(59,2 \% ; 95 \% \mathrm{CI}, 51.5$ per- 66,8$)$ and respiratory systems $(55,9 \%$; $95 \%$ CI $49,3-64,1)$.

Comparison of the frequency of co morbidity across classes of diseases found significant age differences: diseases of the circulatory system $(\mathrm{OR}=19,1 ; 95 \% \mathrm{CI}$ of $12.1-31,4 ; \mathrm{p}=0,042)$ and the endocrine system often is diagnosed in elderly patients $(\mathrm{OR}=6,1 ; 95 \% \mathrm{CI}$ of 3.2 to $15.9 ; \mathrm{p}=0.001$ ), which undoubtedly influenced the initial severity of the clinical manifestations of CHF. Patients younger than 60 years were more likely to have a pathology of the respiratory $(\mathrm{OR}=2.6 ; 95 \%$ CI 1.4-5.8; $\mathrm{p}=0.037)$, digestive $(\mathrm{OR}=2.5 ; 95 \%$ CI $1.3-5.7 ; \mathrm{p}=0.033)$ and genitourinary $(\mathrm{OR}=3.4 ; 95 \% \mathrm{CI} 1.8-7.6 ; \mathrm{p}=0.008)$ systems.

Comparative analysis of the main indicators in the age group older than 60 years $(n=67)$ and $<60$ years $(n=85)$ showed no statistically significant differences in such parameters as the presence of multiple coronary artery lesions and the frequency of preoperative myocardial infarction. However, a statistically significant difference of indicators such as frequency of III-IV FC according to CCS (OR=5,5; 95\% CI of 1.3 to $23.3 ; \mathrm{p}=0,033)$, ejection fraction of the left ventricle less than $40 \%(\mathrm{OR}=7,4 ; 95 \% \mathrm{CI}$ of $2.1-31,4 ; \mathrm{p}=0,014), 3$ or more risk factors of the operation $(\mathrm{OR}=16.5 \mathrm{CM}$; 95\% CI, 3.8 to 19.4 per; $\mathrm{p}=0.004)$, points on the logistic indicator EuroScore, $(4.2[3.2 ; 4.7]$ against $2.2[1.6 ; 2.9] \mathrm{p}=0.045)$. All these data objectively confirm a greater operational risk in patients in the age group over 60 years and an increase in the projected hospital mortality. 
Charlson comorbidity index (CCI) was 4.9 [4.2-5.5] points. It should be noted that CCI allows to predict mortality, which is $12 \%$ in the absence of comorbidity, with $1-2$ points $-26 \%$; with $3-4$ points $-52 \%$, and with more than 5 points $-85 \%$. Thus, low CCI $(\leq 3)$ was most often diagnosed in patients younger than 60 years $(37.6 \%$ vs. $16.4 \%$, $\mathrm{p}=0.04)$, high $(>5)$-in patients older than 60 years $(58.7 \%$ vs. $35.3 \%, \mathrm{p}=0.04)$. In addition, CCI correlated with the following postoperative complications: heart failure requiring inotropic support for more than 5 days $(\mathrm{r}=0.69)$; perioperative MI $(\mathrm{r}=0.64)$; acute acute violation of cerebral circulation confirmed by computed tomography $(\mathrm{r}=0.55)$; cardiac arrhythmias (atrial fibrillation, paroxysmal ventricular tachycardia) $(\mathrm{r}=0.51)$; respiratory failure leading to prolonged artificial lung ventilation for more than 5 days $(\mathrm{R}=0.46)$.

\section{Conclusion}

Comorbidity in CABG is characterized in elderly and senile patients by a high risk of adverse prognosis (survival is less than $21 \%$ in the next 10 years). The presence of a significant frequency of both multi and co morbid diseases determines the high associated operational and anesthetic risk, which should be taken into account at the stage of preoperative preparation in gerontological patients. Also it requires additional examination, increased costs and mandatory medical correction.

\section{Acknowledgments}

None.

\section{Conflicts of interest}

Author declares there is no conflict of interest in publishing the article.

\section{References}

1. Gaughan J, Kobel C. Coronary artery bypass grafts and diagnosis related groups: patient classification and hospital reimbursement in 10 European countries. Health Econ Rev. 2014;10;4:4.

2. Vakhitov D, Oksala N, Saarinen E, et al. Suominen V survival of patients and treatment-related outcome after intra-arterial thrombolysis for acute lower limb ischemia. Ann Vasc Surg. 2019;55:251-259.

3. Van Oostrom SH, Picavet HS, de Bruin SR, et al. Multimorbidity of chronic diseases and health care utilization in general practice. BMC Fam Pract. 2014;15(1):61.

4. Szychta W, Majstrak F, Opolski G, et al. Change in the clinical profile of patients referred for coronary artery bypass grafting from 2004 to 2008 . Trends in a single-centre study. Kardiol Pol. 2015;73(7):493-501.

5. Akça B, Erdil N, Colak MC, et al. Is There any difference in risk factors between male and female patients in new-onset atrial fibrillation after coronary artery bypass grafting?. Thorac Cardiovasc Surg. 2018;66(6):483-490.

6. Prados TA, Calderón LA, Hancco SJ, et al. Multimorbidity patterns: a systematic review. J Clin Epidemiol. 2014;67(3):254- 266.

7. http://www.who.int/mediacentre/factsheets/fs310_2011.pdf

8. Eagle KA, Guyton RA, Davidoff R, et al. ACC/AHA guidelines for coronary artery bypass graft surgery: executive summary and recommendations: a report of the american college of cardiology/ american heart association task force on practice guidelines (committee to revise the 1991 guidelines for coronary artery bypass graft surgery). Circulation.1999;4:1464-1480.

9. Piątek J, Kędziora A, Konstanty KJ, et al. Risk factors for in-hospital mortality after coronary artery bypass grafting in patients 80 years old or older: a retrospective case-series study. Peer J. 2016;4(1):e2667. 